\title{
Effects of funding on the collaboration and citation in environmental papers and the relationship with nation's science and technology
}

\section{budgets}

Efeitos do fomento sobre a colaboração e citação de artigos da área ambiental e as relações com orçamentos nacionais de ciência e tecnologia João Carlos Nabout ${ }^{1}$ (), Ruan Carlos Pires Faquim ${ }^{1}$ (), Rodrigo Assis Carvalho ${ }^{1}$ (), Karine Borges Machado ${ }^{1}$ (1)

\section{A B S T RA C T}

Input, output, impact, and processes are central indicators of the science, technology, and innovation production. The input is usually associated to investments made in science and technology, and it varies among different countries and scientific fields. Thus, the input can influence other impact indicators. Here, we evaluated the effect of the input data (i.e., number of funding) on process (i.e., collaboration) and output (i.e., number of citation) indicators of ecological research. Moreover, we detailed the effect of the number of funding on the collaboration and number of citations by each country (based on the nationality of authors). We found that most of published papers had some degrees of financial support, and that the production of papers with funding increased over the years. Funding had a positive effect on the collaboration and citation of papers; however, we observed that: in countries with higher investments in Science and Technology, the number of funding impacts positively and directly on the number of authors (collaboration) and in countries with low levels of investments in Science and Technology, the number of funding impacts positively and directly on the number of citations. Our models presented a low predictive power, but similar to other informetric studies. Our results indicated that impact indicators evaluated have an integrated structure, and the effects at one level can affect other levels. Nonetheless, the impact of the number of funding on informetric data can vary among countries; therefore, these results are important to the development of national policies and future informetric studies.

Keywords: number of authors; collaboration; citation; environmental science; structural equation modeling.

\begin{abstract}
R E S U M 0
Dados de entrada (input), saída (output), impacto e processos são indicadores centrais da produção em Ciência, Tecnologia e Inovação. Oinputestáassociadoaosinvestimentos realizadosemciênciaetecnologia, podendo variar entre diferentes países e áreas científicas. Assim, o input pode influenciar outros indicadores de impacto. Aqui, avaliamos seu o efeito (número de financiamentos) sobre o processo de colaboração e o número de citações (output) da pesquisa ecológica. Além disso, detalhamos o efeito do número de financiamentos sobre a colaboração e o número de citações por país (baseado na nacionalidade dos autores). Verificamos que a maioria dos artigos publicados tinha algum grau de suporte financeiro, e que a produção de artigos com financiamento aumentou ao longo dos anos. O número de financiamentos teve efeito positivo na colaboração e nas citações, porém observamos que: nos países com maior investimento em ciência e tecnologia, o número de financiamentos impacta positivamente e diretamente a colaboração (número de autores); e nos países com menor investimento em ciência e tecnologia, o número de financiamentos impacta positivamente e diretamente as citações. Nossos resultados demonstram que os indicadores de impacto avaliados têm estrutura integrada e os efeitos em um nível podem afetar outros níveis. Entretanto, o impacto do número de fomentos nos indicadores informétricos pode variar entre os países, portanto esse resultado é importante para o desenvolvimento de políticas nacionais e para futuros estudos informétricos.
\end{abstract}

Palavras-chave: número de autores; colaboração; citação; ciências ambientais; modelagem de equações estruturais.

\footnotetext{
${ }^{1}$ Universidade Estadual de Goiás - Anápolis (GO), Brazil.

Correspondence address: João Carlos Nabout - BR 153 - Km 99, 3105 - Fazenda Barreira do Melo - CEP: 75132-903 - Anápolis (GO), Brazil. E-mail: joao.nabout@ueg.br

Conflicts of interest: the authors declare that there are no conflicts of interest.

Funding: Fundação de Amparo à Pesquisa do Estado de Goiás (FAPEG), Conselho Nacional de Desenvolvimento Científico e Tecnológico (CNPp) (proc. 465610/2014-5), and Coordenação de Aperfeiçoamento de Pessoal de Nível Superior (CAPES).
}

Received on: 02/04/2021. Accepted on: 09/03/2021.

https://doi.org/10.5327/Z217694781043

This is an open access article distributed under the terms of the Creative Commons license. 


\section{Introduction}

Indicators of the scientific, technological, and innovative production can be divided into one of the following four groups: input, output, impact, and processes (Moed, 2017). The input refers to investments done in science and technology (Geisler, 2000), and this component has an important contribution to the development of research stages (Lewison and Dawson, 1998). However, input is highly variable among different countries and scientific fields (May, 1998), a phenomenon that creates asymmetries during the stages of the scientific production and, consequently, on impact indicators, such as the number of: articles produced, citations, and acknowledgments referring to project funding (Fortin and Currie, 2013; Rigby, 2013). Other worldwide studies have also explored citation and co-citation, collaboration among authors, impact factor, and h-index among informetric indicators to evaluate the stages of the scientific process (Bar-Ilan, 2008; Mena-Chalco et al., 2014; Nabout et al., 2015; Parreira et al., 2017). Therefore, an important and crucial step to science relies on understanding how investments made in the scientific process are affecting these parameters in different scales, countries, and fields of knowledge.

Funding resources to scientific research are granted by private or public agencies and sectors; however, investments in basic scientific research for most countries come from public resources (Wang et al., 2012). These funding grants contribute to the formation of human resources via scholarships, improvement of laboratorial infrastructure via acquisition of new equipment, creation of research networks with exchange between researchers, and the development of new technologies and patents. Thus, investments in science, technology, and innovation can directly affect other impact indicators, such as citations (output), and number of co-authors and collaboration (processes; Zhao et al., 2018). This situation reinforces the importance of investigating the impacts of funding on scientific processes.

Studies reporting the influence of funding on output data goes back to 1990s (Lewison and Dawson, 1998; Rigby, 2013), but its main use in the informetric literature increased only in the past few years (Paul-Hus et al., 2016; Tang et al., 2017; Mejia and Kajikawa, 2018). This scenario occurred because information about funding resources related to scientific papers was recently included in different databases (e.g., Scopus and Clarivate Analytics databases). Moreover, the validity and the importance of funding data available in the Web of Science (2009) were reported by several other papers (for more details, see Paul-Hus et al., 2016).

The effect of funding on different impact indicators of the scientific production can be represented following one simple association structure, i.e., the number of funding stimulates the collaboration among scientists (more authors involved in the scientific process), and both funding and collaboration produce more papers with a higher level of citations (see Padial et al., 2010; Tahamtan et al., 2016). Nonetheless, considering that the number of funding granted is dependent of the investment level made in science and technology, this association structure describing the effect of funding on impact indicators of the scientific production may vary among different countries (Wang et al., 2012). In fact, many studies have shown that funding has a positive impact on different impact factors of the scientific production, but this effect is not as strong as expected (Jacob and Lefgren, 2011; Fortin and Currie, 2013; Rigby, 2013; Yan et al., 2018). Therefore, understanding the effects of funding on the collaboration and citations of the scientific production from different countries and research fields is a challenge for current scientometric research field and for science in general. Given that the number of ecological studies has increased in the last decades and its global production is affected by geographical and socioeconomic factors (Parreira et al., 2017), it is fundamental to understand how financial support affects impact factors in this research field and if this relationship follows the same patterns observed for other areas.

The aim of this study was to reveal the effect of the input data (number of funding) on process (collaboration) and output (number of citation) of the ecological research field. Moreover, considering the differences of science and technology investments among distinct countries, we detailed the effect of funding on collaboration and number of citations by each country (based on the nationality of authors). We hypothesized that "if ecological research follows the same patterns observed for other scientific fields, papers with a higher number of funding will present a higher number of authors and citations, but with a weak effect size." Moreover, we also investigated whether the number of authors together with the number of funding can affect directly the number of article citations. For this purpose, we evaluated scientific papers of the ecological research field selected from the WoS database using the structural equation modeling (SEM) approach. Therefore, despite several studies in the scientific literature have investigated the influence of funding on collaboration and number of citations (e.g., Jacob and Lefgren, 2011; Fortin and Currie, 2013; Rigby, 2013; Yan et al., 2018), the new aspects of our study rely on: investigating a new and productive research field; evaluating this relationship considering the nationality of the authors; and applying a new methodological approach to reveal direct and indirect effects of funding.

\section{Material and Methods}

\section{Funding data in WoS}

Funding data presented in WoS from Clarivate Analytics have three different fields: "Funding Text" (FT), "Funding Agency" (FO), and "Grant Number" (FG). FT returns the full text written by authors in the Acknowledgments section of their article(s). FO gives the name of agencies and organizations cited in the FT field. FG indicates grant numbers, which are associated with both FO and FT fields. Thus, FG represents all kinds of funding received by authors, and sometimes many of these grants are from the same agency. In this study, we used funding data information from the FG field. We choose to use only WoS from Clarivate Analytics because it has a long temporal range for funding information 
(since 2009), and to standardize this type of data since distinct databases may present a different number of citations for the same paper.

\section{Data collection}

We selected all papers published in the category "Ecology" between 2010 and 2016, considering all scientific journals indexed in WoS. We started our search in 2010 because from that year our database was complete (i.e., funding data was available to all papers). We selected Ecology because it is a broad scientific area that is composed of professionals from various subareas with distinct histories and scientific behaviors (e.g., Neff and Corley, 2009; Nabout et al., 2015; Parreira et al., 2017). Moreover, with the growing concern to maintain global biodiversity and sustainable environmental policies, resources from public and private agencies have been allocated to ecological research. Therefore, there is a demand of the civil society for evaluating the effect of scientific investments on the informetric impact indicators (e.g., production of articles, citation, and collaboration, among others) of the ecological research field.

We searched the papers in the WoS from Clarivate Analytics ISI database (searched in December of 2017), using index SCI-Expand and SSCI. For this study, we selected only original articles, and the following data were obtained from each paper:

- number of funding grants, indicated by FG;

- time of publication (number of years after the publication);

- number of authors;

- number of citations;

- nationality of all authors.

For nationality, if all authors were from same country, the paper was classified as national collaboration, and if at least two authors were from different countries the paper was classified as international collaboration. This is especially important to analyze the influence of funding in national collaboration papers (see below). All papers used in this study and their classification (number of funding, number of authors, nationality, etc.) are available in Supplementary file (ESM 1).

Investments in science, technology, and innovation (STI) were obtained for 55 countries of our database (corresponding to 69,430 papers, or $97 \%$ of total national collaboration papers). Investments in STI correspond to the investment in dollars by habitants and it was obtained in the database of the Organisation for Economic Co-operation and Development (OECD, www.data.oecd.org). The STI has been used by informetric papers (e.g., Cimini et al., 2016; Dranev et al., 2018), and it usually indicates the national policy of investment in science, including resource to infrastructure and scholarships, among others (OECD, 2017).

\section{Data analysis}

We used the SEM to investigate the effects of input indicators on output and processes of indicators, determining their direct and indi- rect effects. The SEM has been widely used in different research fields of science (e.g., Bag, 2015; Lefcheck, 2016; Shaheen et al., 2017), and, for particular questions of the present paper, the advantage of using SEM, instead the traditional linear regression model or other statistical tests, is because it considers the structural association among predictor variables. This association is based on a conceptual model of the research. We elaborated the conceptual model based on the idea that direct effects are observed from input data on the process and output of literature, and from process on the output (Figure 1). According to this conceptual model, we are capable of identifying relationships among latent variables which can be represented by many observation variables. In the present study, we used three types of observation variables to indicate the input, output, and process latent variables: number of funding, number of citation, and number of authors (indicating scientific collaboration), respectively. For citation, we divided the number of citations of a given paper by the time of publication to control the effect of the time on the number of citations. According to our hypothesis, all coefficients (a, b, and c) in SEM will be positive, indicating a positive effect of the number of funding on the number of authors and citations. Moreover, we expected to find a positive effect of the number of authors on citations. All variables used in SEM were $\log$-transformed $(\log X+1)$, and all coefficients were standardized, thus the variables (number of funding, number of authors, and citations) were transformed to variables with mean of zero and standard deviation of one.

The evaluation of SEM was based on Tucker-Lewis Index (TLI), ranged between 0 and 1.0, with best fit found at 1.0. A value of TLI higher than 0.9 indicates an excellent model ( $\mathrm{Hu}$ and Bentler, 1999). We selected this index because it is independent of the sample size (Bentler, 1990; Fan et al., 2016). Assumptions of the SEM are similar to those made in linear regression models; therefore, it is necessary to deal with normality of variables, independence of sampling unities, and homoscedasticity. Considering that informetric data often have a skewed distribution, we used the bootstrap approach to solve this problem (see Ory and Mokhtarian 2010; Knief and Forstmeier, 2021). In the present study, we used to each SEM 1000 bootstrap and the estimator was the maximum likelihood.

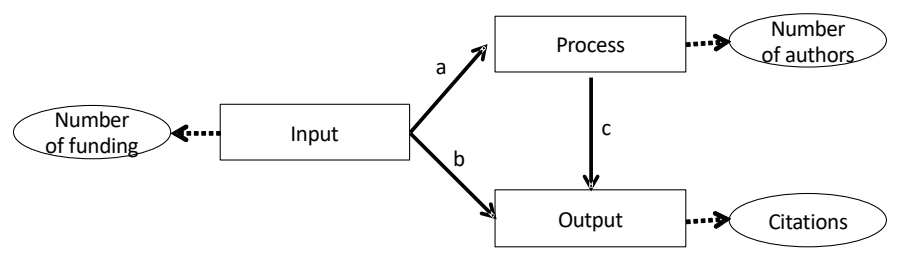

Figure 1 - Structural modeling. Boxes represent latent variables and circles represent observation variables. The relationship is indicated by solid arrows. (A) The input can affect directly the process and (B) the output. (C) The process can affect the output. 
In SEM, the main unity of analysis was the paper, and we proposed four SEMs for the following scenarios:

- all papers in the same analysis;

- national papers, performing the analysis with papers where all authors are from same country;

- international papers, performing the analysis with papers where all authors are from different countries;

- papers by country (authors from same country presented in protocol 2).

Posteriorly, we related the coefficients ( $a, b$, and c of the SEM) with the investment in STI of each country.

We performed a linear regression to investigate if the three coefficients described in SEM analyses were associated with the investments in science of evaluated countries. The significance of each regression slope was tested according to a null model using 999 iterations during a Monte Carlo procedure (Manly, 2006).

The SEM was performed using the function "sem" in package "lavaan" (Rosseel, 2012), and for linear regression models was the function "lm" of package "stat," both in software R (R Core Team, 2021).

\section{Results}

We found a total of 116,589 papers of Ecology indexed in the WoS, of which $71,028(61 \%)$ of the papers with national collaboration and 45,561 (39\%) of the papers with international collaboration. We also found that the number of ecological papers published increased over the years and the growth rate of papers with international collaboration is higher than the observed rate for papers with national collaboration, even though the number of papers with national collaboration was higher (Figure 2).

Our findings demonstrated that approximately $82.8 \%$ of all papers published had at least one source of funding, and an increase in the number of papers with funding along the temporal series was considered. For example, in 2010 , a total of $78.9 \%$ of papers had at least one funding, whereas in 2016, the number of papers with funding increased to $85.1 \%$ (Figure 3). Additionally, the temporal trend of papers with more than one funding has increased over the years, whereas the number of papers without funding has decreased (Figure 3).

The SEM using all papers showed that the number of funding has a positive effect on the number of authors and citations (Figure 4A). In details, the number of funding presented a positive direct effect on the number of authors and a positive indirect effect on the number of citations. The direct effect of funding on citations was lower (considering the coefficient), but in general all models presented a low predictive power $\left(\mathrm{R}^{2}\right.$, Figure $\left.4 \mathrm{~A}\right)$. We divided the dataset into papers with authors from same country (namely, national collaboration) and papers with authors from different countries (namely, international collaboration). Overall, the SEMs for national (Figure 4B) and international collaboration presented the same pattern of global data (Figure 4C).

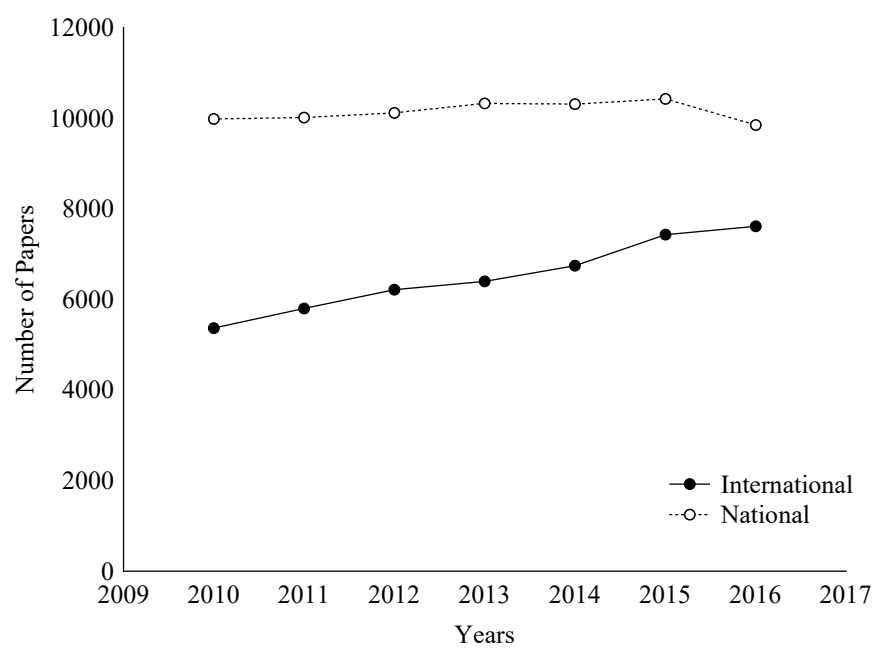

Figure 2 - Number of papers along the years considering the nationality of authors, where "international" indicates authors from different countries, and "national" indicates all authors from the same country.

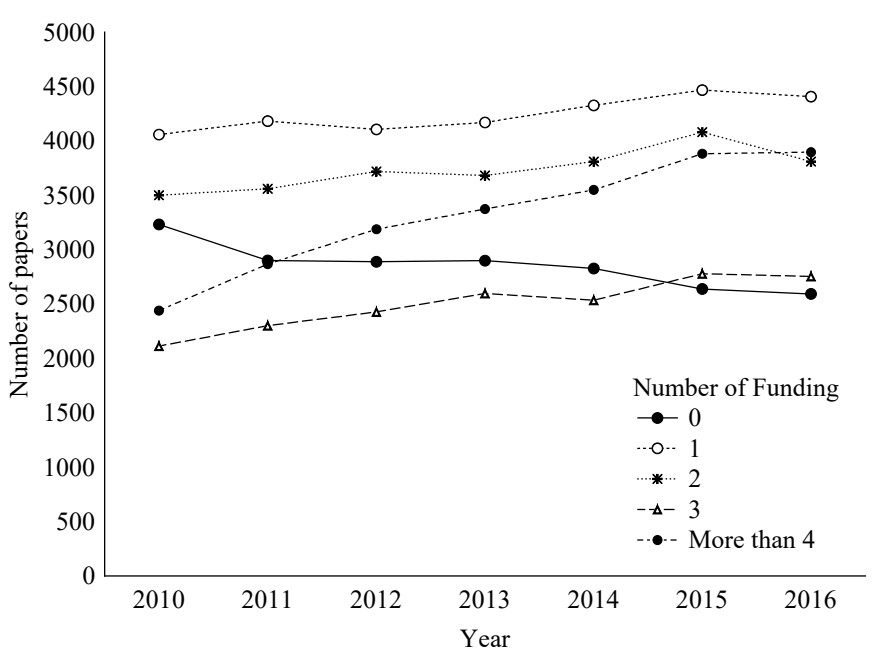

Figure 3 - Number of funding by papers along the years. Scientific papers were divided into five categories, according to the number of funding registered.

However, international collaboration presented a higher $\mathrm{R}^{2}$, highlighting the importance of international collaboration in these informetric indicators. All SEMs (global, national, and international) presented excellent models (TLI $=1$ ).

We also used SEM to evaluate the effect of the number of funding on number of authors and citations of papers by each country separately (using only papers with authors from the same country). We obtained SEM coefficients ( $a, b$, and c) for the 55 most productive countries evaluated (see the results for each country in the ESM2). For all countries, there was a predominance of positive co- 

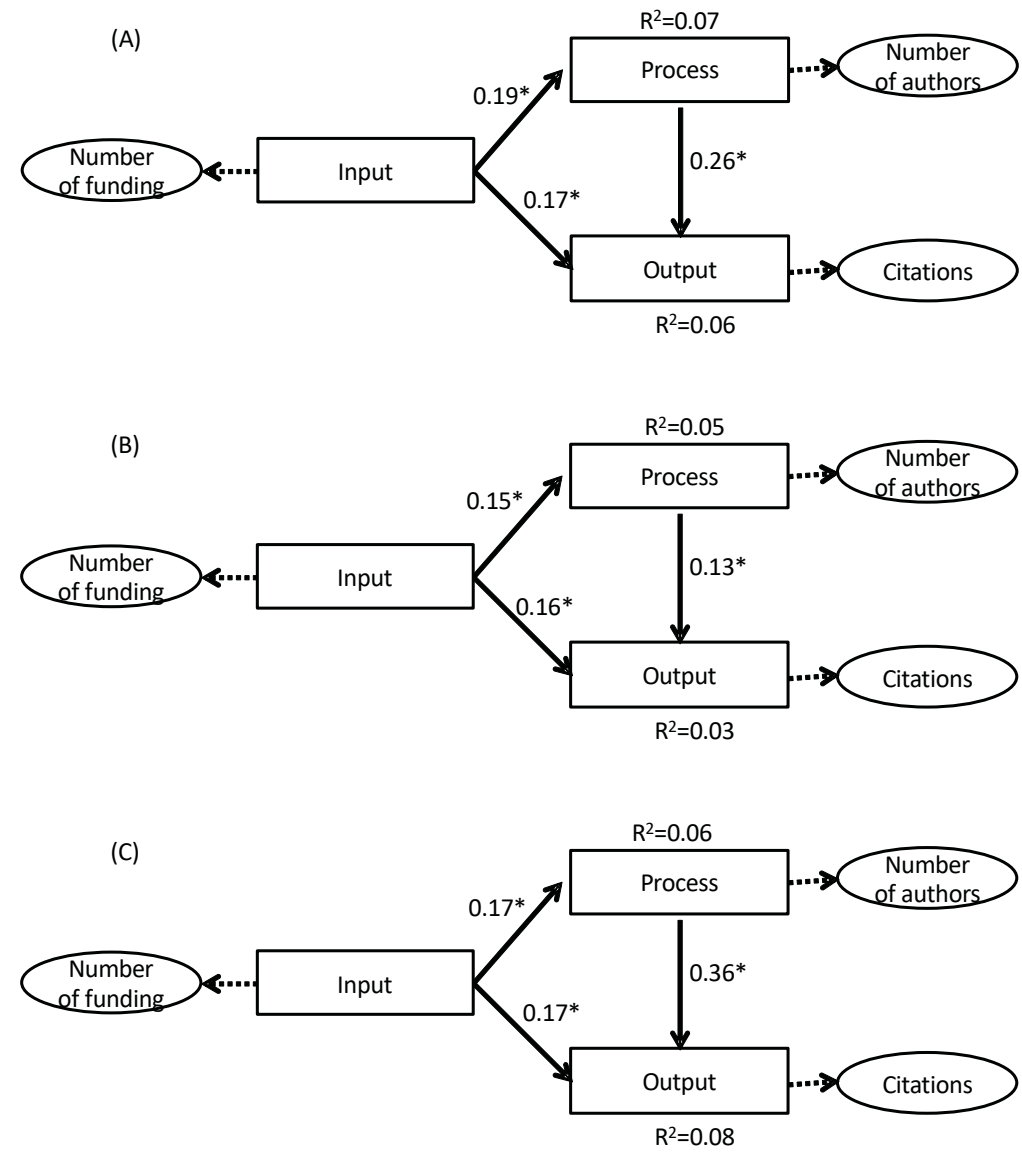

Figure 4 - SEM with standardized coefficient (solid arrows) using all papers. Boxes represent latent variables and circles represent observed variables used in present study. Papers used in SEM were analyzed considering: (A) papers with national (authors from the same country) and international (authors from different countries) collaboration, representing all our dataset; (B) papers with national collaboration; and (C) papers with international collaboration. ${ }^{*} \mathrm{p}<0.001$.

efficients; in addition, there was variation in the coefficients among countries grouped based on the categories of investment investigated. For the coefficient a, which measures the influence of the input (number of funding) on the process (number of authors), it was observed that countries with the highest investments presented the highest coefficients a $\left(\mathrm{R}^{2} \mathrm{adj}=0.27 ; \mathrm{p}<0.001\right.$; Figure $\left.5 \mathrm{~A}\right)$. It means that papers with more authors were those with a greater number of funding, and this fact was more recurrent in countries with higher levels of investment in STI. In contrast, the coefficient $\mathrm{b}$ that measures the influence of the input (number of funding) on the output (number of citations) was higher in countries with lower investments in STI, indicated by the negative slope of linear regression $\left(\mathrm{R}^{2} \mathrm{adj}=0.06 ; \mathrm{p}<0.03\right.$; Figure $\left.5 \mathrm{~B}\right)$. The coefficient $\mathrm{c}$ that measures the influence of the process on citations was positive indicating that it is more frequent in countries with high investments on STI that papers with more authors present a greater number of citations $\left(\mathrm{R}^{2} \mathrm{adj}=0.17 ; \mathrm{p}=0.001\right.$; Figure $5 \mathrm{C}$ ). These results showed that funding can have different impacts on informetric indicators, depending on the amount of investments in STI. In countries with high investments in STI, the number of funding affects directly the number of authors and indirectly the number of citations; whereas in countries with low investments in STI, the number of funding affects directly the number of citations of papers.

\section{Discussion}

The present study evaluated the influence of the number of funding on the collaboration among scientists and citation of scientific articles in ecological research; in addition, this effect was disentangled based on different countries and their level of investments in STI. Our main results indicate that the number of funding in ecological papers increased along the years, and we also detected a positive effect of the number of funding on number of authors and citations of papers. Nonetheless, deconstructing these effects per country revealed that countries with a higher degree of financial investments in STI maintained a similar relationship with the global data production of papers. In contrast, countries with a lower degree of investments in STI showed 

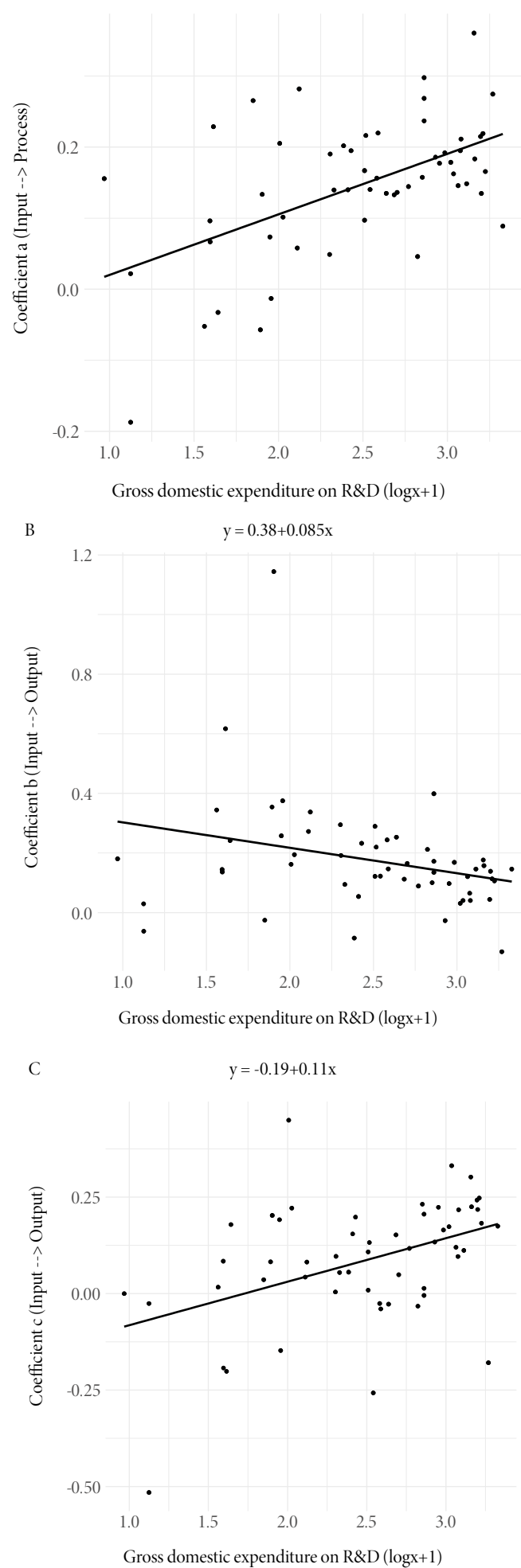

Figure 5 - Scatterplot of each coefficient obtained in SEM and the country investment in science, technology, and innovation. (A) Coefficient a of the SEM, indicating the effect of funding on the number of authors; (B) coefficient $b$ of the SEM, indicating the effect of funding on the number of citations; and (C) coefficient $c$ of the SEM, indicating the direct effect of the number of authors and the indirect effect of the number of funding on the number of citations. that the number of funding impacts citations positively and directly. Therefore, future papers aiming to investigate the number of funding and its influences on informetric parameters of impact must consider the nationality of co-authors, once funding policies and absolute values invested in STI vary among countries.

Despite the positive impact of research funding on several impact indicators of the scientific production, recent studies also showed that this effect is not high (Jacob and Lefgren, 2011; Fortin and Currie, 2013; Rigby, 2013; Yan et al., 2018). Our findings indicate that this trend is also observed for ecological research, and, additionally, there is a positive relationship between the number of authors and citations, as also found by other authors (Leimu and Koricheva, 2005b; Padial et al., 2010). Several factors, such as presence of positive results (Leimu and Koricheva, 2005b; Fanelli, 2013), larger network of collaboration (Leimu and Koricheva, 2005a; Yu et al., 2014; Parreira et al., 2017), high number of pages (Bornmann et al., 2014), visibility of papers (open-access papers are more cited; Xia et al., 2011), visibility at online social media (Nabout et al., 2018), publication in prestige journals (Vanclay, 2013), among others (see Tahamtan et al., 2016; Bai et al., 2019), may affect the number of citations and authors of a paper. Given that we did not include all these variables in our models, this may explain their low predictive power. Therefore, in absolute values, the $\mathrm{R}^{2}$ was low; however, considering the few number of variables used, we concluded that the number of funding can be an important variable affecting informetric data.

The number of funding is an important indicator of the input, and it is recognized that the diversity of funding agencies and types of funding (research investments, scholarships, and exchange) can strengthen the scientific research and promotes an increase on the collaboration among authors and citation of articles (Bowen and Casadevall, 2015; Tahamtan et al., 2016). In the same way, the absolute value invested by research or papers can affect other informetric indicators (e.g., Leydesdorff et al., 2019). In fact, in the present study, it is not possible to determine the total value invested on each paper, and thus the metric number of funding is an indicator of the diversity of investments for a given article. Therefore, an article with more funding sources has a greater capacity for authors to raise funds for research. In this sense, we demonstrated that articles with the highest number of funding were those with the highest number of authors and citations.

Investments in science have historically raised knowledge and promoted innovation and social and economic growth (Lane and Bertuzzi, 2011). However, each country has its own idiosyncrasies related to how much it invests in scientific development, reflecting in a different number of researchers per country, and/or in consolidated and stable sources of funds. These differences exist even in time of crisis when each country decides how to invest in science and technology. For example, the European Union countries increase their investment in science during the period of economic crisis (e.g., Makkonen, 2013), while Brazil has experienced an economic recession and political crisis which has impacted in the investments in STI (Angelo, 2019; Thomé 
and Haddad, 2019). Considering these historical differences among countries, the number of funding (and also the raw amount of resources invested) generates different impacts on science and processes of collaboration and citations of scientific papers. Here, we demonstrated that the number of funding affected positively the number of collaborations in countries with greater investments in STI (usually developed countries), whereas the number of funding was positively related to the number of citations in countries with lower number of investments. These differences influence on the dynamics of science in countries.

In developed countries with greater investments in STI, the competitiveness per resource to promote research is higher. Therefore, larger groups of authors increase the chance of raising funds (Lewison and Dawson, 1998). In contrast, in countries with fewer investments, funding increases the quality of the scientific paper produced, impacting on the number of citations. Evidently, related mechanisms cannot be explained by few variables. The relationship between investments and number of citations can be influenced by several aspects, such as funding sources (national or international), their variety (number of funders), and intensity (Gök et al., 2016). Besides funding, numerous other factors can be determinants for citations (Padial et al., 2010). Therefore, this study took a step forward in detecting the influence of the number of funding on informetric indicators according to countries and their level of investment in STI.

The effect of the number of funding on informetric indicators also highlights the importance of investments in STI to improve indicators of collaboration and citations of papers. Collaboration has been an important element in increasing the quantity and quality of science. In fact, studies have shown that the number of papers with international collaboration has increased over the years (Parreira et al., 2017), and that the mobility of researchers promotes an increase in the quality of the papers produced (Sugimoto et al., 2017). This mobility involves investment; therefore, the lack of investment can limit collaboration between researchers. Some countries have been promoting specific calls for mobility (national and international), for example, the program Erasmus Mundus (Europe Union), British Council with State of Brazilian Government, among others.

\section{Conclusion}

The present paper demonstrates that effects at one level of the informetric indicator can affect other indicators and levels. Moreover, we highlight that the impact of the number of funding can vary among countries, therefore, these results are important to the development of national policies and future informetric studies. To national policy, the number of funding can affect directly or indirectly the number of citations and this structure depends of the level of investments in STI made by each country. In countries with higher investments in STI, we found that funding affects directly the number of collaboration and indirectly the number of citation; whereas in countries with fewer investments in STI, funding affects directly the number of citations. To future informetric studies, we recommend the inclusion of author's nationality when investigating the funding effect. Although our conclusions were based on ecological data, we believe that other biological, medical, physic and chemistry areas can presented similar patterns given they present a similar structure of scientific production, collaboration and citations.

\section{Acknowledgments}

We thank editor and two anonymous reviewers that helped to improve and clarify this manuscript.

\section{Contribution of authors:}

Nabout, J.C.: Conceptualization, Formal Analysis, Writing - first draft, Writing - edition \& review. Faquim, R.C.P.: Data curation, Formal analysis, Writing - first draft, Writing - edition \& review. Carvalho, R.A.: Conceptualization, Formal Analysis, Writing — first draft, Writing — edition \& review. Machado, K.B.: Conceptualization, Formal Analysis, Writing — first draft, Writing — edition \& review.

\section{References}

Angelo, C., 2019. Brazil's government freezes nearly half of its science spending. Nature, v. 568, 155-156.

Bag, S., 2015. A short review on structural equation modeling: applications and future research directions. Journal of Supply Chain Management Systems, v. $4,(3) 64-69$.

Bai, X.; Zhang, F.; Lee, I., 2019. Predicting the citations of scholarly paper. Journal of Informetrics, v. 13, (1), 407-418. https://doi.org/10.1016/j. joi.2019.01.010.

Bar-Ilan, J., 2008. Review Informetrics at the beginning of the $21^{\text {st }}$ century - A review. Journal of Informetrics, v. 2, (1), 1-52. https://doi.org/10.1016/j. joi.2007.11.001.
Bentler, P.M., 1990. Comparative fit indexes in structural models. Psychological Bulletin, v. 107, (2), 238-246. https://doi.org/10.1037/00332909.107.2.238.

Bornmann, L.; Leydesdorff, L.; Wang, J., 2014. How to improve the prediction based on citation impact percentiles for years shortly after the publication date? Journal of Informetrics, v. 8, (1), 175-180. https://doi.org/10.1016/j. joi.2013.11.005.

Bowen, A.; Casadevall, A., 2015. Increasing disparities between resource inputs and outcomes, as measured by certain health deliverables, in biomedical research. Proceedings of the National Academy of Sciences, v. 112, (36), 11335-11340. https://doi.org/10.1073/pnas.1504955112. 
Cimini, G.; Zaccaria, A.; Gabrielli, A., 2016. Investigating the interplay between fundamentals of national research systems: Performance, investments and international collaborations. Journal of Informetrics, v. 10, (1), 200-211. https://doi.org/10.1016/j.joi.2016.01.002.

Dranev, Y.; Kotsemir, M.; Syomin, B., 2018. Diversity of research publications: relation to agricultural productivity and possible implications for STI policy. Scientometrics, v. 116, (3), 1565-1587. https://doi.org/10.1007/s11192-0182799-2.

Fan, Y.; Chen, J.; Shirkey, G.; John, R.; Wu, S. R.; Park, H.; Shao, C., 2016. Applications of structural equation modeling (SEM) in ecological studies: an updated review. Ecological Processes, v. 5, (1), 1-12. https://doi.org/10.1186/s13717-016-0063-3.

Fanelli, D., 2013. Positive results receive more citations, but only in some disciplines. Scientometrics, v. 94, (2), 701-709. https://doi.org/10.1007/s11192012-0757-y.

Fortin, J.-M.; Currie, D.J., 2013. Big science vs. little science: how scientific impact scales with funding. Plos One, v. 8, (6), e65263. https://doi.org/10.1371/ journal.pone.0065263.

Geisler, E. 2000. The metrics of science and Technology. Quorum Books, New York.

Gök, A.; Rigby, J.; Shapira, P., 2016. The impact of research funding on scientific outputs: Evidence from six smaller European countries. Journal of the Association for Information Science and Technology, v. 67, (3), 715-730. https://doi.org/10.1002/asi.23406.

Hu, L.T.; Bentler, P.M. 1999. Cutoff criteria for fit indexes in covariance structure analysis: conventional criteria versus new alternatives. Structural Equation Modeling, v. 6, (1), 1-55. https://doi. org/10.1080/10705519909540118.

Jacob, B.A.; Lefgren, L., 2011. The impact of research grant funding on scientific productivity. Journal of Public Economics, v. 95, (9-10), 1168-1177. https://doi.org/10.1016/j.jpubeco.2011.05.005.

Knief, U.; Forstmeier, W., 2021. Violating the normality assumption may be the lesser of two evils. Behavior Research Methods, 1-15. https://doi.org/10.3758/ s13428-021-01587-5.

Lane, J.; Bertuzzi, S., 2011. Measuring the results of science investments. Science, v. 331, (6018), 678-680. https://doi.org/10.1126/science.1201865.

Lefcheck, J.S., 2016. Piecewise SEM: Piecewise structural equation modelling inr for ecology, evolution, and systematics. Methods in Ecology and Evolution, v. 7, (5), 573-579. https://doi.org/10.1111/2041-210x.12512.

Leimu, R.; Koricheva, J. 2005a. Does scientific collaboration increase the impact of ecological articles? BioScience, v. 55, (5), 438-443. https://doi. org/10.1641/0006-3568(2005)055[0438:DSCITI]2.0.CO;2.

Leimu, R.; Koricheva, J., 2005b. What determines the citation frequency of ecological papers? Trends in Ecology \& Evolution, v. 20, (1), 28-32. https://doi. org/10.1016/j.tree.2004.10.010.

Lewison, G.; Dawson, G., 1998. The effect of funding on the outputs of biomedical research. Scientometrics, v. 41, (1-2), 17-27. https://doi. org/10.1007/BF02457963.

Leydesdorff, L.; Bornmann, L.; Wagner, C.S., 2019. The relative influences of government funding and international collaboration on citation impact. Journal of the Association for Information Science and Technology, v. 70, (2), 198-201. https://dx.doi.org/10.1002\%2Fasi.24109.

Makkonen, T., 2013. Government science and technology budgets in times of crisis. Research Policy, v. 42, (3), 817-822. https://doi.org/10.1016/j. respol.2012.10.002.
Manly, B.F., 2006. Randomization, bootstrap and Monte Carlo methods in biology (Vol. 70). CRC Press, Boca Raton.

May, R.M., 1998. The scientific investments of nations. Science, v. 281, (5373), 49-51. https://doi.org/10.1126/science.281.5373.49.

Mejia, C.; Kajikawa, Y., 2018. Using acknowledgement data to characterize funding organizations by the types of research sponsored: The case of robotics research. Scientometrics, v. 114, (3), 883-904. https://doi.org/10.1007/s11192-017-2617-2.

Mena-Chalco, J.P.; Digiampietri, L.A.; Lopes, F.M.; Cesar Junior, R.M., 2014. Brazilian Bibliometric Coauthorship Networks. Journal of the Association for Information Science and Technology, v. 65, (7): 1424-1445. https://doi. org/10.1002/asi.23010.

Moed, H.F., 2017. Applied evaluative informetrics. Springer, Amsterdam.

Nabout, J.C.; Parreira, M.R.; Teresa, F.B.; Carneiro, F.M.; Cunha, H.F; Souza Ondei, L.; Caramori, S.S.; Soares, T.N., 2015. Publish (in a group) or perish (alone): the trend from single-to multi-authorship in biological papers. Scientometrics, v. 102, 357-364. https://doi.org/10.1007/s11192-014-1385-5.

Nabout, J.C.; Teresa, F.B.; Machado, K.B.; Prado, V.H.M.; Bini, L.M.; Diniz-Filho, J.A.F., 2018. Do traditional scientometric indicators predict social media activity on scientific knowledge? An analysis of the ecological literature. Scientometrics, v. 115, (2), 1007-1015. https://doi. org/10.1007/s11192-018-2678-x.

Neff, M.W.; Corley, E.A., 2009. 35 years and 160,000 articles: A bibliometric exploration of the evolution of ecology. Scientometrics, v. 80, (3), 657-682. https://doi.org/10.1007/s11192-008-2099-3.

Organization for Economic Co-operation and Development - OECD. 2017. OECD Science, Technology and Industry Scoreboard 2017: The digital transformation. OECD, Paris (Accessed December 1, 2019) at: http://dx.doi. org/10.1787/9789264268821-en.

Ory, D.T.; Mokhtarian, P.L., 2010. The impact of non-normality, sample size and estimation technique on goodness-of-fit measures in structural equation modeling: evidence from ten empirical models of travel behavior. Quality \& Quantity, v. 44, (3), 427-445. https://doi.org/10.1007/s11135-008-9215-6.

Padial, A.A.; Nabout, J.C.; Siqueira, T.; Bini, L.M.; Diniz-Filho, J.A.F., 2010. Weak evidence for determinants of citation frequency in ecological articles. Scientometrics, v. 85, 1-12. https://doi.org/10.1007/s11192-010-0231-7.

Parreira, M.R.; Machado, K.B.; Logares, R.; Diniz-Filho, J.A.F.; Nabout, J.C., 2017. The roles of geographic distance and socioeconomic factors on international collaboration among ecologists. Scientometrics, v. 113, (3), 15391550. https://doi.org/10.1007/s11192-017-2502-z.

Paul-Hus, A.; Desrochers, N.; Costas, R., 2016. Characterization, description, and considerations for the use of funding acknowledgement data in Web of Science. Scientometrics, v. 108, (1), 167-182. https://doi.org/10.1007/s11192-016-1953-y.

R Core Team. 2021. R: A language and environment for statistical computing. R Foundation for Statistical Computing, Vienna, Austria (Accessed September 19, 2017) at: https://www.R-project.org/.

Rigby, J., 2013. Looking for the impact of peer review: does count of funding acknowledgements really predict research impact? Scientometrics, v. 94, (1), 57-73. https://doi.org/10.1007/s11192-012-0779-5.

Rosseel, Y., 2012. lavaan: An R Package for Structural Equation Modeling. Journal of Statistical Software, v. 48, (2), 1-36. https://doi.org/10.18637/jss. v048.i02.

Shaheen, F.; Ahmad, N.; Waqas, M.; Waheed, A.; Farooq, O., 2017. Structural equation modeling (SEM) in social sciences \& medical research: a guide for improved analysis. International Journal of Academic Research in Business 
and Social Sciences, v. 7, (5), 132-143. http://dx.doi.org/10.6007/IJARBSS/v7i5/2882.

Sugimoto, C.R.; Robinson-García, N.; Murray, D.S.; Yegros-Yegros, A.; Costas, R.; Larivière, V., 2017. Scientists have most impact when they're free to move. Nature News, v. 550, (7674), 29-31. https://doi. org/10.1038/550029a.

Tahamtan, I.; Afshar, A. S.; Ahamdzadeh, K., 2016. Factors affecting number of citations: a comprehensive review of the literature. Scientometrics, v. 107, (3), 1195-1225. https://doi.org/10.1007/s11192-016-1889-2.

Tang, L.; Hu, G.; Liu, W., 2017. Funding acknowledgment analysis: Queries and caveats. Journal of the Association for Information Science and Technology, v. 68, (3), 790-794. https://doi.org/10.1002/asi.23713.

Thomé, M.T.C.; Haddad, C.F.B., 2019. Brazil's biodiversity researchers need help. Science, v. 364, (6446), 1144-1145. https://doi.org/10.1126/science. aax9478.

Vanclay, J.K., 2013. Factors affecting citation rates in environmental science. Journal of Informetrics, v. 7, (2), 265-271. https://doi.org/10.1016/j. joi.2012.11.009.
Wang, X.; Liu, D.; Ding, K.; Wang, X., 2012. Science funding and research output: a study on 10 countries. Scientometrics, v. 91, (2), 591-599. https://doi. org/10.1007/s11192-011-0576-6.

Web of Science. 2009. Funding Acknowledgements (Accessed December 5, 2017) at: http://wokinfo.com/products_tools/multidisciplinary/webofscience/ fundingsearch/.

Xia, J.; Myers, R.L.; Wilhoite, S.K., 2011. Multiple open access availability and citation impact. Journal of Information Science, v. 37, (1), 19-28. https://doi. org/10.1177\%2F0165551510389358.

Yan, E.J.; Wu, C.J.; Song, M., 2018. The funding factor: a cross-disciplinary examination of the association between research funding and citation impact. Scientometrics, v. 115, (1), 369-384. https://doi.org/10.1007/s11192017-2583-8.

Yu, T.; Yu, G.; Li, P.Y.; Wang, L., 2014. Citation impact prediction for scientific papers using stepwise regression analysis. Scientometrics, v. 101, 1233-1252. https://doi.org/10.1007/s11192-014-1279-6.

Zhao, S.X.; Lou, W.; Tan, A.M.; Yu, S., 2018. Do funded papers attract more usage? Scientometrics, v. 115, (1), 153-168. https://doi.org/10.1007/s11192018-2662-5. 